\title{
ZnO-assisted coating of tetracalcium phosphate/ gelatin on the polyethylene terephthalate woven nets by atomic layer deposition
}

https://doi.org/10.1515/epoly-2020-0010

Received July 19, 2019; accepted October 23, 2019.

\begin{abstract}
A new kind of coating consisting of zinc oxide (ZnO)/tetracalcium phosphate (TTCP)/gelatin (Gel) on the PET woven nets is prepared chemically by the method of atomic layer deposition (ALD) and hydrothermal method. The prepared materials are confirmed by XRD and SEM. $\mathrm{XRD}$ results show that $\mathrm{ZnO}$ and TTCP are well coated on the surface of PET woven nets and ALD-assisted ZnO leads to a surprising coating adhesion of about $8 \mathrm{MPa}$. Furthermore, SEM results indicate the diameter and morphology of $\mathrm{ZnO}$, TTCP and Gel of PET woven nets. And the water contact angles of PET's surface are decreased with $\mathrm{ZnO}$, TTCP and Gel of PET woven nets. Moreover, the confocal imaging of NIH3T3 cells shows that the obtained product could promote the cells proliferation, which indicates that the good biocompatibility of the prepared PET/ZnO/TTCP/ Gel woven builds a foundation for their future application. The results aim to obtain an efficient method to modify PET for fabricating an ideal artificial implant meeting the clinical needs, and imply a positive effect in promoting the compatibility of PET for enhancing graft-bone healing after implantation.
\end{abstract}

\footnotetext{
* Corresponding authors: Jiejun Cheng, Department of Radiology, Shanghai Renji Hospital, Shanghai Jiao Tong University School of Medicine, 1630 Dongfang Rd, Shanghai 200127, P. R. China, email: drchjj@163.com; Jun Zhu, National Engineering Research Center for Nanotechnology, 28 East Jiangchuan Road, Shanghai 200241, P. R. China, email: yzjzhu@163.com; Dannong He, School of Materials Science and Engineering, Shanghai Jiao Tong University, 800 Dongchuan Road, Shanghai 200240, P. R. China; National Engineering Research Center for Nanotechnology, 28 East Jiangchuan Road, Shanghai 200241, P. R. China, email: hdn_nercn@163.com Xinyi Zhang, School of Materials Science and Engineering, Shanghai Jiao Tong University, 800 Dongchuan Road, Shanghai 200240, P. R. China

Juan Zhou, National Engineering Research Center for Nanotechnology, 28 East Jiangchuan Road, Shanghai 200241, P. R. China
}

Keywords: atomic layer deposition; PET woven nets; zinc oxide; tetracalcium phosphate; gelatin

\section{Introduction}

Polyethylene terephthalate (PET) material has been applied to the biomedical devices for its excellent mechanical strength, including artificial ligament, artificial vessel, heart valve closure, surgical suture and so on (1). However, it is difficult for cells to adhere and proliferate on PET fibers due to a low surface energy of PET. Thus, to overcome the disadvantages of PET biological inertness and improve the interaction between PET and host tissues, scientists have widely studied on the surface modification of PET material (2-6). Many bioactive materials or hydrophilic polymers have been used for the coating of PET materials for their medical and biomedical applications such as surgical drapes, vascular grafts and ligament prostheses (7-10). Nevertheless, although some surface modifications based on different chemical reactions have been reported, it is difficult to carry out the surface modification on PET material with a high coating adhesion due to the chemical inertia, high crystallinity and hydrophobic specialties of PET.

Atomic layer deposition (ALD) is a surface-controlled layer-by-layer process that results in the deposition of thin films one atomic layer at a time. The self-limited character of ALD ensures the growth of uniform and conformal films, with film thickness controlled at the atomic level (11). Until now, many materials have been obtained through ALD technology (12). In addition, atomic level control and low deposition temperature allow for a precise coating on biological templates, including $\mathrm{TiO}_{2}$ and $\mathrm{Al}_{2} \mathrm{O}_{3}$ on tobacco Mosaic virus, fungus hair, ferritin, etc. (13,14). Furthermore, compared with other nanostructure fabrication techniques, ALD on the biological template can accurately control monodisperse 
functional units determined by the information encoded in DNA. Moreover, the obtained ALD films with different crystal structures can be obtained by adjusting the substrate temperature (15), which provides a potential opportunity for the growth of other materials based on crystal surface matching (16). Therefore, based on the above previous reports, ALD would be a good substitute for PET surface modification.

Calcium phosphate ceramics is one of important biomedical bioactive ceramic materials, which composed of $\mathrm{HA}\left(\mathrm{Ca}_{5}\left(\mathrm{PO}_{4}\right)_{3}(\mathrm{OH})\right)$, TTCP $\left(\mathrm{Ca}_{4}\left(\mathrm{PO}_{4}\right)_{2} \mathrm{O}\right)$, $\alpha$-TCP $\left(\mathrm{Ca}_{3}\left(\mathrm{PO}_{4}\right)_{2}\right), \beta$-TCP $\left(\mathrm{Ca}_{3}\left(\mathrm{PO}_{4}\right)_{2}\right)$, and so on. These calcium phosphate ceramics are always used as a surface modifier for bioactive coating on hard or soft material, including titanium alloy, stainless steel, PET, polyetheretherketone (PEEK), and so on, from some strategies of plasma spray, sol-gel, electrochemical deposition, etc. In the present experiment, we develops a novel surface modification based on our research results of the preparation about a nanoscale surface roughness $\mathrm{ZnO}$ film by ALD technology changes their matrix adhesion (17-18), which means that the deposition of $\mathrm{ZnO}$ with ALD technique is used to obtain a coating on PET woven nets. Furthermore, the combination of the advantages of TTCP and gelatin gives a good choice for the artificial bioactive coatings. Therefore, a novel $\mathrm{PET} / \mathrm{ZnO} / \mathrm{TTCP} / \mathrm{Gel}$ woven net is prepared, which shows a good adhesion between the coating and PET woven nets of about $8 \mathrm{MPa}$. To be specific, the current study is carried out in terms of two folds: (1) to obtain an efficient method to modify PET for fabricating an ideal artificial implant meeting the clinical needs, (2) to imply a positive effect in promoting the compatibility of PET for enhancing graft-bone healing after implantation.

\section{Experimental}

\subsection{Pretreatment of PET woven nets}

The PET woven nets were immersed in an ethanol solution for $0.5 \mathrm{~h}$ and then treated by sonication to remove surface adhesive impurities. After being washed with distilled water to remove the residual ethanol at room temperature, PET woven nets were further boiled in $1 \%$ sodium hydroxide solution for $1 \mathrm{~h}$. Then, the obtained PET was washed with plenty of distilled water until the $\mathrm{pH}$ value of the wash solution was near neutral. Finally, the carboxyl exposed PET woven nets were obtained after being dried at $60^{\circ} \mathrm{C}(19)$.

\subsection{ZnO deposition on PET woven nets}

ZnO was deposited on PET woven nets using Picosum R-150 ALD UNIT. Diethylzine (DEZ, purity > 99.99\%) was used as $\mathrm{Zn}$ precursor, and water was used as $\mathrm{O}$ precursor. The two precursors were pulsed into the reaction chamber alternately with a high nitrogen (purity > 99.999\%) as carrier gas. A complete ALD cycle consists of two precursor pulses and two purge processes. The pulse time of precursors was $0.1 \mathrm{~s}$, and the puege times for DEZ and water 3 and $4 \mathrm{~s}$, respectively. During deposition, the pressure of chamber was kept about $1400 \mathrm{~Pa}$ by an oil pump, and the substrate temperature was set to $150^{\circ} \mathrm{C}$. The number of ALD cycles was fixed at 300, and the obtained product was recorded by PET/ZnO woven nets.

\subsection{Hydrothermal synthesis of TTCP on $\mathrm{PET} / \mathrm{ZnO}$ woven nets}

$1 \mathrm{~mol} / \mathrm{L}$ calcium nitrate solution and $0.6 \mathrm{~mol} / \mathrm{L}$ orthophosphoric acid solution were put into a three-necked bottle with the $\mathrm{Ca} / \mathrm{P}$ ratio of 2:1. Then, urea was put into the above solution as the mass ratio of $5 \%$. After being stirred for several minutes, $25 \%$ ammonia solution was added to adjust $\mathrm{pH}$ to 10 at $40^{\circ} \mathrm{C}$ for $4 \mathrm{~h}$. The obtained solution and PET woven nets were transferred to polytetrafluoroethylene lined autoclave and then kept for $6 \mathrm{~h}$ at $90^{\circ} \mathrm{C}$. Finally, $\mathrm{PET} / \mathrm{ZnO} / \mathrm{TTCP}$ woven nets were produced after washed by distilled water and dried $60^{\circ} \mathrm{C}$ for $12 \mathrm{~h}$.

\subsection{Adsorption of Gel on PET/ZnO/TTCP woven nets}

The prepared PET/ZnO/TTCP PET woven nets were immersed in the Gel solution at different content of $1 \%$, $5 \%$ and $10 \%(\mathrm{w} / \mathrm{w})$ for $24 \mathrm{~h}$. The obtained woven nets were kept at drying oven at $60^{\circ} \mathrm{C}$ for $24 \mathrm{~h}$ after being washed by deionized water, whose product was recorded as $\mathrm{PET} / \mathrm{ZnO} / \mathrm{TTCP} / \mathrm{Gel}$ woven nets.

\subsection{Characterization}

The thickness of ALD ZnO on the Si wafer under the same deposition situation to the $\mathrm{ZnO}$ deposition on PET woven nets was measured by ellipsometer (W-VASE with AutoRetarder, J.A. Woollam CO., Inc. USA), and then the deposition rate was calculated. The phase and purity of the obtained product was determined by powder X-ray 
diffraction (XRD) (RigakuD/MAXIIA diffractometer using $\mathrm{Cu}$ Ka radiation). Energy dispersive X-ray (EDX) analysis was recorded on field- emission scanning electron microscope (FESEM, Hitachi, S-4800). The coating adhesion was performed according to ASTM D751-2005 by an electronic universal testing machine (CXT-4104, MTS Systems Corporation, Eden Prairie, MN, USA). Surface wettability was characterized by static water contact angle measurement (JC2000C1, Zhongchen Co., Ltd.).

\subsection{Confocal imaging of cells}

Confocal imaging of cells was performed using a Leica laser scanning confocal microscope (Wetzlar, Germany). NIH3T3 cells $\left(1 \times 10^{6}\right.$ cells $\left.\cdot \mathrm{mL}^{-1}\right)$ were incubated with PET/ZnO/TTCP/ Gel woven nets for $2 \mathrm{~h}$ for confocal imaging, fixed with $4 \%$ paraformaldehyde for $30 \mathrm{~min}$, and stained by DAPI for $8 \mathrm{~min}$. All cells were washed twice with PBS before confocal imaging from 1 to 6 days of culturing time. Imaging of NIH3T3 cells was carried out at the laser excitation of $364 \mathrm{~nm}$, with the maximum emission peak is $454 \mathrm{~nm}$.

\section{Results and discussion}

The $\mathrm{ZnO} / \mathrm{TTCP} / \mathrm{Gel}$ coated PET woven nets are prepared by the following three-step procedure: After the carboxyl group exposure of the PET woven nets, $\mathrm{ZnO}$, TTCP and Gel was deposited on PET woven nets, orderly. Among them, $\mathrm{ZnO}$ is deposited by ALD technology and TTCP was grown by hydrothermal synthesis, in which $\mathrm{ZnO}$ deposition is a key step for the strong coating adhesion between PET woven nets and coating. Thus, as shown in Figure 1, the PET woven net is first treated with $\mathrm{NaOH}$ to expose the carboxyl groups to the surface (19), which can greatly alter the activation and hydrophobicity of the PET woven nets. Furthermore, $\mathrm{ZnO}$ is coated on a clean PET woven net by placing $\mathrm{ZnO}$ in an atomic layer deposition instrument, which can cover a $\mathrm{ZnO}$ film with nanometers on the surface of PET woven nets with a deposition rate of $0.13 \mathrm{~nm} /$ circle. Then, the above PET nets are immersed in calcium and phosphate salt solution to hydrothermally grow TTCP because of a possible crystal face matching between TTCP and $\mathrm{ZnO}(15,16)$.

EDS and XRD analyses were performed to identify the chemical component and crystalline nature of the deposit surface. EDS analyse shows 1.01, 0.54 and $2.27 \mathrm{~mol} \%$ about $\mathrm{Ca}, \mathrm{P}$ and $\mathrm{Na}$ element, respectively, meaning an average $\mathrm{Ca} / \mathrm{P}$ ratio of 1.87 . The result is different from the $\mathrm{Ca} / \mathrm{P}$ ratio of normal HA (1.67), which implies a possible newly formed surface-deposit as matching the $\mathrm{Ca} / \mathrm{P}$ ratio $(20,21)$. Moreover, the desired $\mathrm{Zn}$ element with $0.06 \mathrm{~mol} \%$ is found in the final product of PET/ZnO/TTCP woven nets, but the atomic percentages of $\mathrm{Zn}$ element is $5.72 \mathrm{~mol} \%$ in the intermediate product of PET/ZnO woven nets, which confirms the presence of ZnO. Furthermore, Figure 2 shows the typical XRD pattern of the obtained products. As shown in curve a, the refection peaks labeled by circle can be indexed to the main lattice plane of PET, but the other refection peaks marked by circle asterisk can contribute to the

\section{Zn precursor}
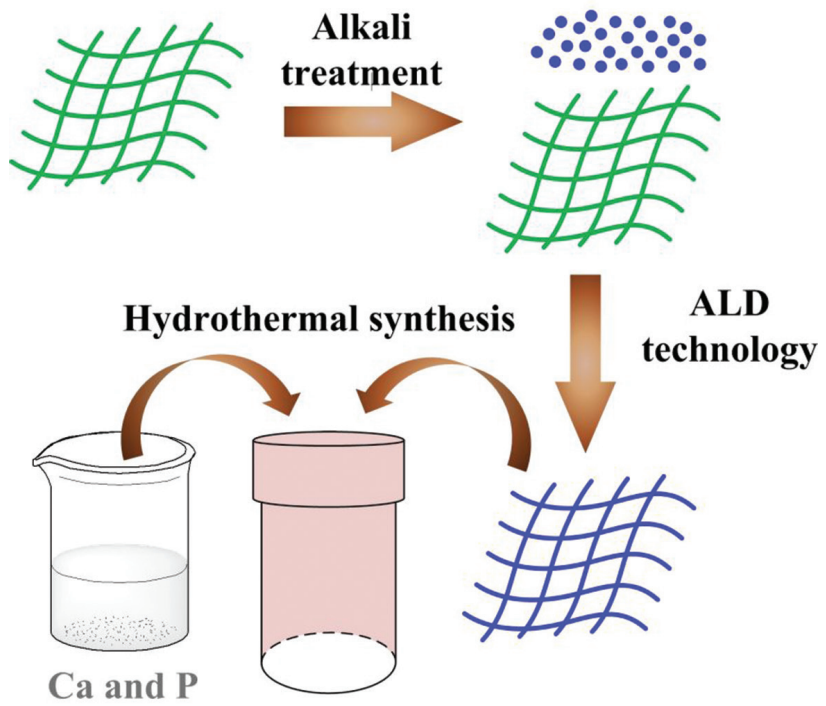

Figure 1: The procedure of the preparation of the $\mathrm{ZnO} / \mathrm{TTCP}$ coated PET woven nets.

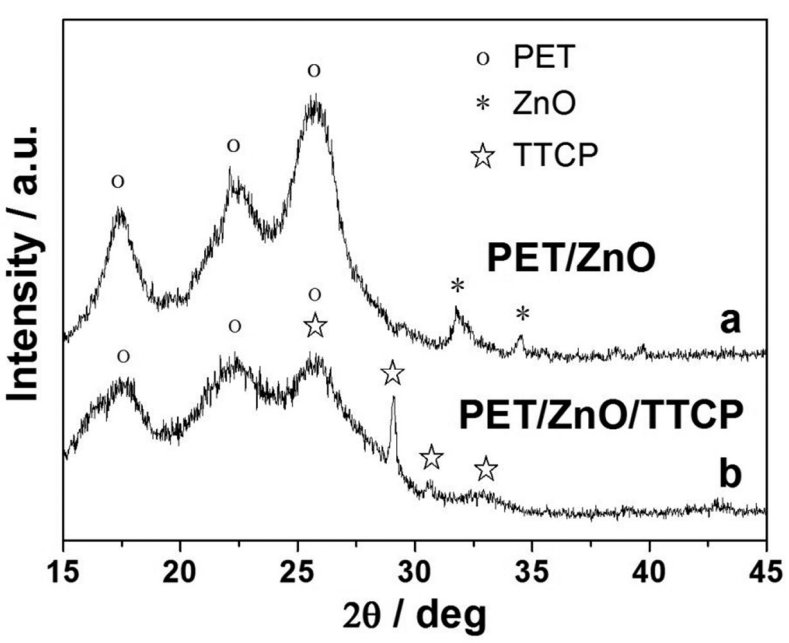

Figure 2: The XRD patterns of PET/ZnO and PET/ZnO/TTCP woven nets. 
main peak of $\mathrm{ZnO}$ (JCPDS 80-0074). Closer observation shows that (002) and (001) crystals appear, but the normal strongest peak of (101) crystal face is invisible, which indicates a poor crystallization of $\mathrm{ZnO}$ amorphous structure and meanwhile implies a thin $\mathrm{ZnO}$ film about few nanosize in thickness on the surface of PET woven nets. The result implies that $\mathrm{ZnO}$ can be coated on the surface of PET woven nets successfully for the formation of PET/ZnO woven nets. Furthermore, calcium phosphate is characterized after the hydrothermal treatment of PET/ZnO woven nets. As shown in curve b, beside the typical PET diffraction peaks, the peaks of $\mathrm{ZnO}$ phases disappear and the present of the major peaks of TTCP phases is located at respectively $25.4^{\circ}, 29.1^{\circ}, 30.6^{\circ}$ and $32.4^{\circ}$ (JCPDS 70-1379). The result is obvious different from the previous many reports on calcium phosphate coating by the matter of HA and TCP. Closer observation shows that the peak widening seems to occur as indicated by the enlargement of the peak at $25.4^{\circ}$ and $32.4^{\circ}$ and the absence of $\mathrm{ZnO}$ phases could contribute to a thick cover, which proves that the diffracting amorphous matter significantly obtains in importance on the surface of PET woven nets with a $\mathrm{ZnO}$ transition layer. The results show amorphous $\mathrm{ZnO}$ obtained by ALD technology helps to modify PET by amorphous TTCP. Therefore, it is feasible of the preparation of TTCP modified woven nets through ZnO deposition by ALD technology and further TTCP growth by hydrothermal treatment.

The morphology of PET, PET/ZnO and PET/ZnO/ TTCP woven net is characterized by SEM. As shown in Figure 3, the average diameter of the PET woven nets is about $20 \pm 1.3 \mu \mathrm{m}$, and their surface looks smooth after being treated by $\mathrm{NaOH}$ (Figure 3a). However, the surfaces are slightly rough and the average diameter is increased to about $22 \pm 1.8 \mu \mathrm{m}$ by $\mathrm{ZnO}$ deposition by ALD technique (Figure $3 b)$. A closer look reveals that the deposition is coated on the surface of PET woven nets (Figure 3c). A partially magnified SEM image (marked with a circle in Figure 3c) indicates that many nanoparticles are well-dispersed with approximately $20 \mathrm{~nm}$ in uniform sizes (Figure 3d). The results imply that the PET woven nets are covered with $\mathrm{ZnO}$ deposition in nanometer sizes. Furthermore, TTCP is grown by hydrothermal synthesis followed by an ALD process. As shown in Figure 3e, their surfaces became rough and the average diameter is further increased to about $27 \pm 2.1 \mu \mathrm{m}$, which could attribute to the coverage of a large amount of irregular TTCP. The cracked portion marked with a circle in Figure 3e shows a thick coating of TTCP modification, which can be attributed to a significant broadening of the fiber diameter. In addition, the enlarged SEM image shows a large amount of irregular coverage on the surface of the woven net (Figure 3f). These results indicate that TTCP can be strongly modified on PET woven nets with the assistance of $\mathrm{ZnO}$ nanoparticles produced by ALD technology.

Due to its potential biomedical applications in the body, Gel is further coated on the PET/ZnO/TTCPP woven nets to obtain good biological activity. The PET/ZnO/ TTCP woven nets were immersed in 1, 5 and 10\% (w/w) Gel aqueous solution, which is characterized by SEM. As shown in Figure 4, as the content of Gel increases, the average diameter increases from $27 \pm 2.1 \mathrm{~mm}$ to $30 \pm 3.2 \mathrm{~mm}$ (Figures $4 \mathrm{a}, 4 \mathrm{c}$ and $4 \mathrm{e}$ ), and the fibers of the PET woven nets look smoother and smoother (Figures 4b, 4d and 4f). The results imply that the PET/ZnO/TTCP woven nets are covered with a large amount of organic matter. Thus, compared to the images of Figures $4 \mathrm{a}$ and $4 \mathrm{~b}$, it is plane for the fibers of the PET woven nets in Figures 4c-f, which contributes to the presence of poorly conductive Gel. Therefore, a $\mathrm{ZnO} / \mathrm{TTCP} / \mathrm{Gel}$ composite coating on PET woven nets is successfully prepared in this experiment. According to the previous reports $(22,23)$, the hydrophilic property of polymer surface always can be evaluated by the water contact angle. As shown in Figure 5, the contact angle decreased from $92^{\circ}$ to $42^{\circ}$ after the application of different coating. Specially, PET's surface water contact
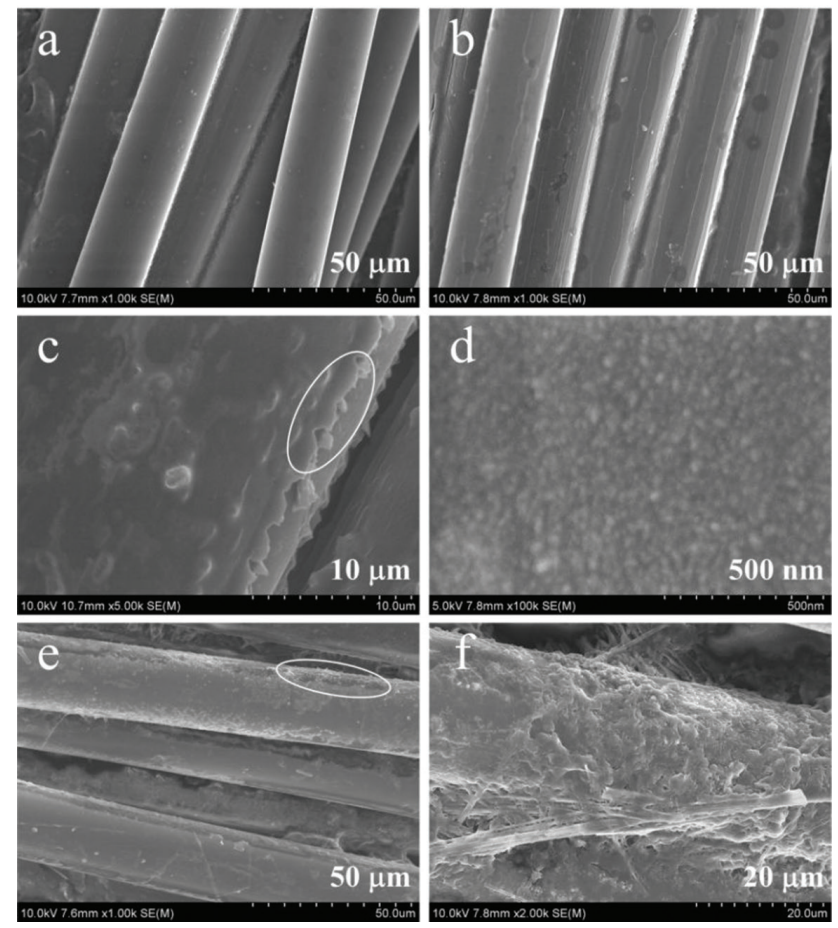

Figure 3: SEM images of PET (a), PET/ZnO (b-d) and PET/ZnO/TTCP $(e, f)$ woven nets. 
angle with treatment by $\mathrm{NaOH}$ is $92^{\circ}$ (Figure 5a), which is low than a net PET (24), indicating that the original PET surface is hydrophilic. After $\mathrm{ZnO}$ deposition by ALD and TTCP coating by hydrothermal synthesis, the water contact angles decrease to $78^{\circ}$ and $65^{\circ}$ (Figures $5 \mathrm{~b}$ and $5 \mathrm{c}$ ), respectively, indicating that the hydrophilicity of the PET surface increases along with further material's
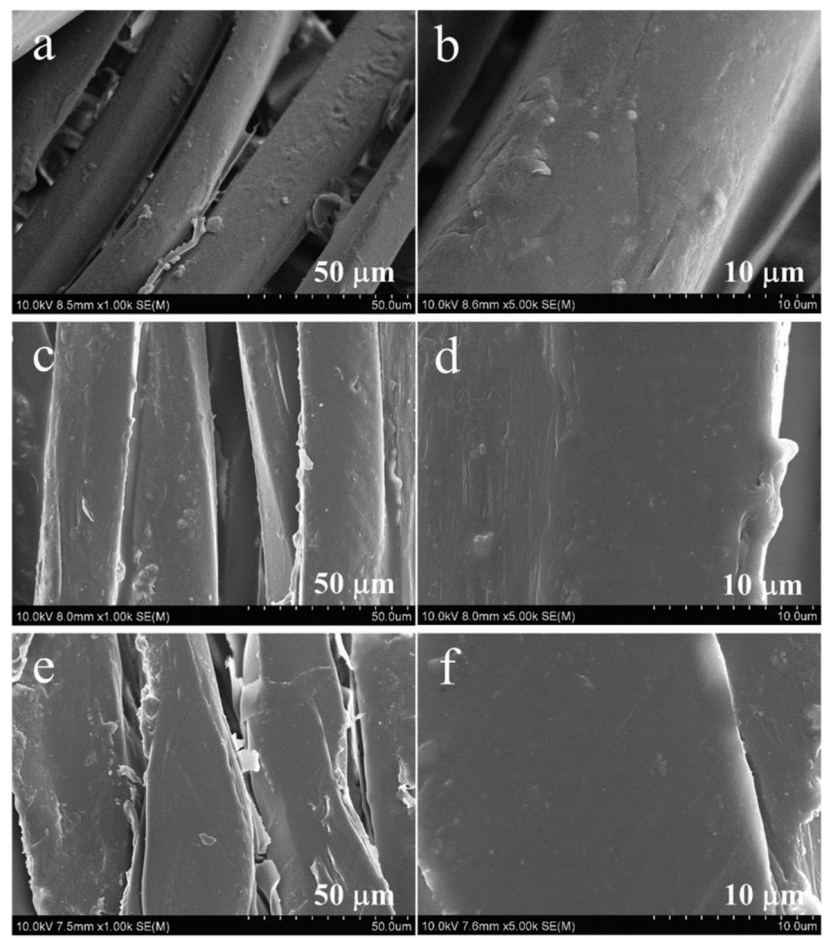

Figure 4: SEM of the PET/ZnO/TTCP/Gel woven nets with different Gel content: $1 \%(\mathrm{a}, \mathrm{b}), 5 \%(\mathrm{c}, \mathrm{d})$ and $10 \%(\mathrm{e}, \mathrm{f})$. modification, which can attribute to hydrophilic materials and porous structure. Furthermore, Gel contributes to a more hydrophilic surface, which results from a water contact angle of $42^{\circ}$ (Figure $5 \mathrm{~d}$ ).

The adhesion of $\mathrm{ZnO} / \mathrm{TTCP} / \mathrm{Gel}$ coating on PET woven nets is evaluated according to ASTM D751-2005, the Standard Test Methods for Coated Fabrics. Based on our homemade jig (Figure 6a), the coating adhesion is about $8 \mathrm{MPa}$ (Figure 6b), which may result from a composite chemical reactions of $\mathrm{ZnO}$ deposition on surface on PET woven nets by ALD technology compactly and then TTCP growth on $\mathrm{ZnO}$ surface through a hydrothermal synthesis.

It is necessary to assess the bioactive characteristics of PET/ZnO/TTCP/Gel woven nets, because they could be potentially used in biomedical applications. Figure 7 shows the CLSM photographs of NIH3T3 cells incubated on the woven nets for 1, 2, 3, 4, 5 and 6 days. When the cells were grown on the PET/ZnO/TTCP/Gel woven nets, the number of cells is increased over time, indicating that the cells proliferated well with increasing days. The results imply that the PET/ZnO/TTCPP/Gel woven nets have good

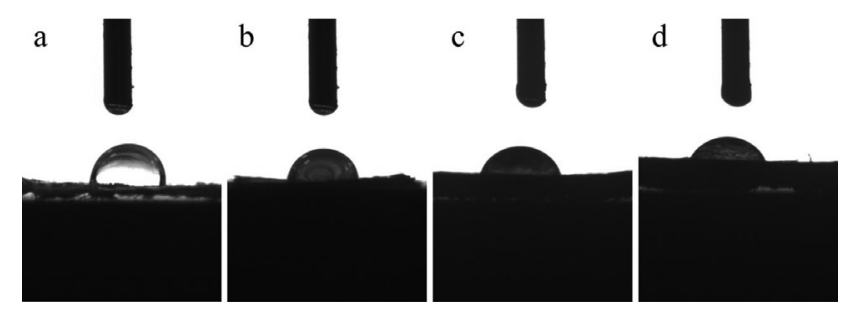

Figure 5: Water contact angle image of carboxyl exposed PET (a), $\mathrm{PET} / \mathrm{ZnO}$ (b), PET/ZnO/TTCP (c) and PET/ZnO/TTCP/Gel (d) woven nets.
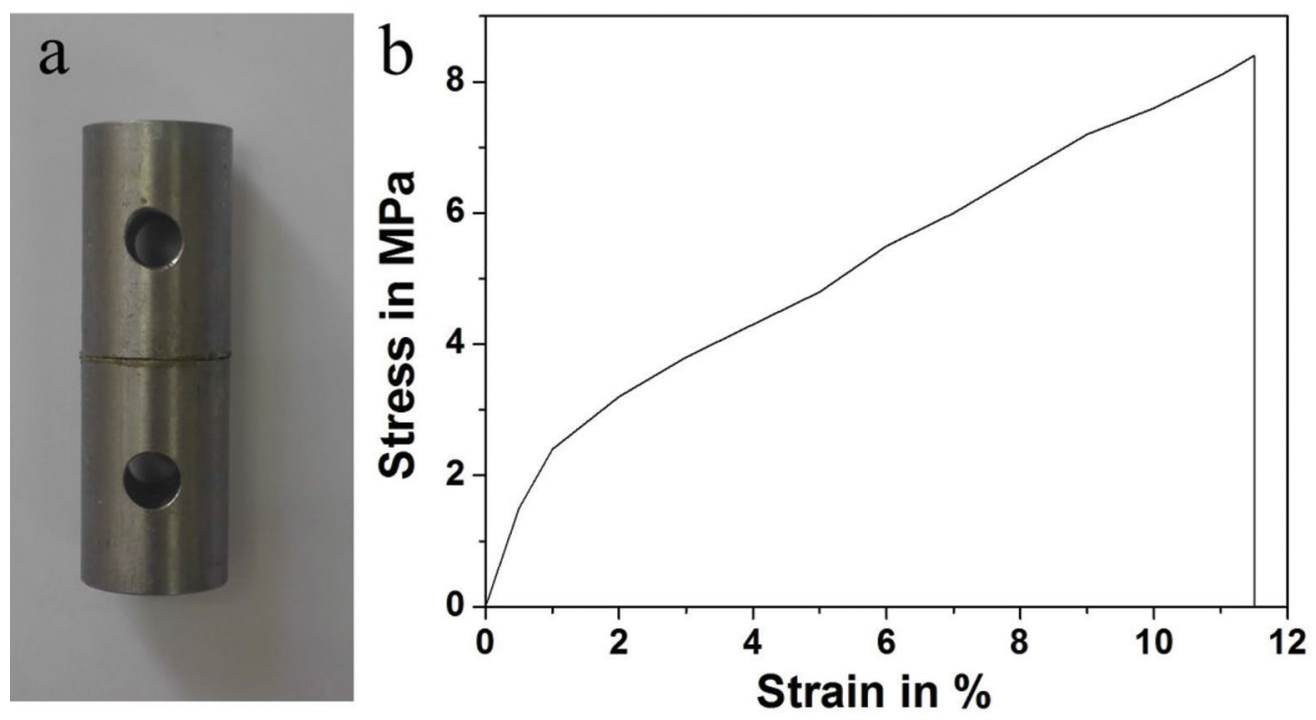

Figure 6: The jig photo (a) and the curve (b) of the coating adhesion between $\mathrm{ZnO} / \mathrm{TTCP} /$ Gel coating and PET woven nets. 

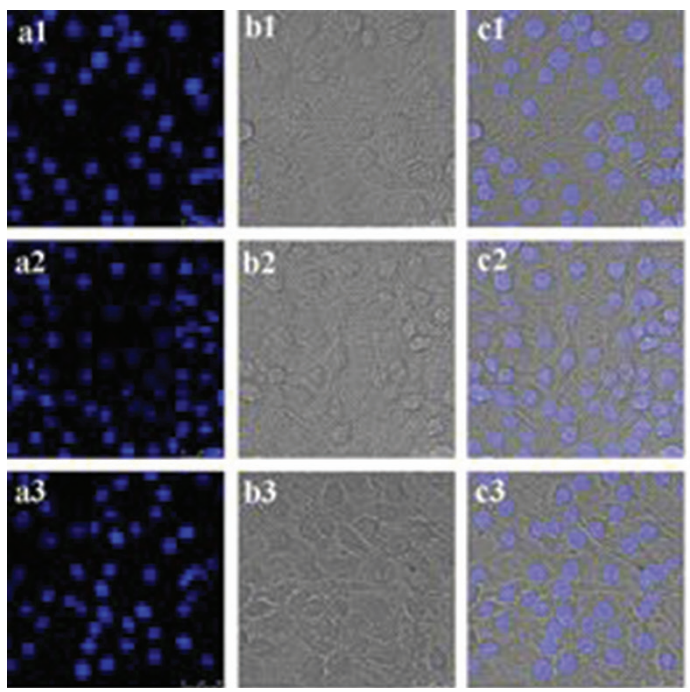
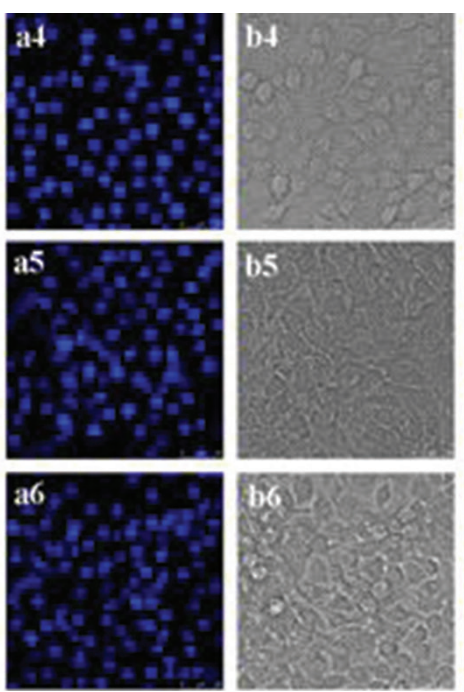
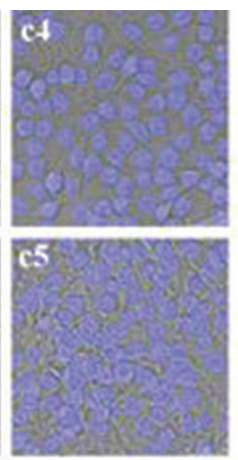

Figure 7: The fluorescent images of cells incubated on the PET/ZnO/TTCP/Gel woven nets for 1 day (a1,b1,c1), 2 day (a2,b2,a2), 3 day $(\mathrm{a} 3, \mathrm{~b} 3, \mathrm{c} 3), 4$ day $(\mathrm{a} 4, \mathrm{~b} 4, \mathrm{c} 4), 5$ day $(\mathrm{a} 5, \mathrm{~b} 5, \mathrm{c} 5)$ and 6 day $(\mathrm{a} 6, \mathrm{~b} 6, \mathrm{c} 6)$ under the identical instrumental conditions at $100 \times$ magnification and are presented at the same intensity scale.

biocompatibility and biological activity, which lays a good foundation for future applications.

\section{Conclusion}

The PET/ZnO/TTCP/Gel woven nets are prepared by ALD and hydrothermal method, and a strong coating adhesion between $\mathrm{ZnO} / \mathrm{TTCP} / \mathrm{Gel}$ coating and PET woven nets is about $8 \mathrm{MPa}$. The reason can contribute to the chemical growth of ZnO by ALD technology and TTCP by hydrothermal synthesis. The results show that $\mathrm{ZnO}$ nanoparticles can cover on the surface of the PET woven nets, which is used as a medium for further TTCP growth. With $\mathrm{ZnO}$ deposition and TTCP growth, the average diameter increased from $22 \pm 1.8 \mu \mathrm{m}$ to $27 \pm 2.1 \mu \mathrm{m}$, and the surface of the PET woven nets became very rough. Moreover, with the addition of Gel, the average diameter is further increased to $30 \pm 3.2 \mu \mathrm{m}$, but the surface of the PET woven nets looks smoother because a large amount of Gel can be applied on the PET/ZnO/TTCP woven nets. Additionally, the cell experiments reveal that the PET/ZnO/TTCP/Gel woven nets have good biocompatibility and biological activity, which lays a good foundation for its future application.

Acknowledgement: The work was supported by Shanghai Science and Technology Development Fund (No. 17XD1421900 and 17441902700), Shanghai Shenkang
Project (16CR3024A) and Shanghai Key Laboratory of Molecular Imaging (18DZ2260400).

\section{References}

1. Toufik M., Mas A., Shkinev V., Nechaev A., Elharfi A., Schue F., Improvement of performances of PET track membranes by plasma treatment. Eur. Polym. J., 2002, 38(2), 203-209.

2. Qi Z.D., Saito T., Fan Y., Isogai A., Multifunctional Coating Films by Layer-by-Layer Deposition of Cellulose and Chitin Nanofibrils. Biomacromolecules, 2012, 13(2), 553-558.

3. Li L., Zhao N., Liu S., Versatile surface biofunctionalization of poly (ethylene terephthalate) by interpenetrating polymerization of a butynyl monomer followed by "Click Chemistry". Polymer, 2012, 53(1), 67-78.

4. Liang M., Yao J., Chen X., Huang L., Shao Z.Z., Silk fibroin immobilization on poly (ethylene terephthalate) films: Comparison of two surface modification methods and their effect on mesenchymal stem cells culture. Mat. Sci. Eng. C, 2013, 33(3), 1409-1416.

5. Meslmani B.M.A., Mahmoud G.F., Sommer F.O., Lohoff M.D., Bakowsky U., Multifunctional network-structured film coating for woven and knitted polyethylene terephthalate against cardiovascular graft-associated infections. Int. J. Pharm., 2015, 485(1-2), 270-276.

6. Hong L., Chen S.Y., Chen J.W., Chang J., Xu M.C., Sun Y.Y., et al., Mussel-inspired artificial grafts for functional ligament reconstruction. ACS Appl. Mater. Inter., 2015, 7(27), 14708-14719.

7. Vaquette C., Viateau V., Guérard S., Anagnostou F., Manassero M., Castner D.G., et al., The effect of polystyrene sodium sulfonate grafting on polyethylene terephthalate artificial ligaments on invitro mineralisation and invivo bone tissue integration. Biomaterials, 2013, 34(29), 7048-7063.

8. Li M.Y., Deng T.T., Liu S.X., Zhang F.X., Zhang G.X., Superhydrophilic surface modification of fabric via coating with nano- $\mathrm{TiO}_{2}$ 
by UV and alkaline treatment. Appl. Surf. Sci., 2014, 297(4), 147-152.

9. MesImani B.M.A, Mahmoud G.F., Leichtweiã T., Strehlow B., Sommer F.O., Lohoff M.D., et al., Covalent immobilization of lysozyme onto woven and knitted crimped polyethylene terephthalate grafts to minimize the adhesion of broad spectrum pathogens. Mat. Sci. Eng. C, 2016, 58(1), 78-87.

10. Wang C.H., Guo C.H., Pang F., Zhang L.Y., Effects of Graphene Modification on the bioactivation of polyethylene-terephthalatebased artificial ligaments. ACS Appl. Mater. Inter., 2015, 7, 15263-15276.

11. Leskelä M., Ritala M., Atomic layer deposition chemistry: recent developments and future challenges. Angew. Chem., 2003, 42(45), 5548-5554.

12. Knez M., Qin Y., Special issue: functional materials by atomic layer deposition. Chem. Vapor Depos., 2013, 19(4-6), 80-81.

13. Knez M., Kadri A., Wege C., Gösele U., Jeske H., Nielsch K., Atomic layer deposition on biological macromolecules: metal oxide coating of tobacco mosaic virus and ferritin. Nano Lett., 2006, 6(6), 1172.

14. Zhu Y., Caob B., Nicholas R., Mao C.B., Kane M., Atomic layer deposition of $\mathrm{Al}_{2} \mathrm{O}_{3}$ on biological pili substrate. ECS Trans., 2010, 33, 43-48.

15. Chai Z.M., Liu Y.H., Lu X.C., He D.N., Influence of crystal structure on friction coefficient of $\mathrm{ZnO}$ films prepared by atomic layer deposition. Sci. China Technol. Sci., 2016, 59(3), 506-512.

16. Wang Z., Qian X.F., Yin J., Zhu Z.K., Large-scale fabrication of tower-like, flower-like, and tube-like $\mathrm{ZnO}$ arrays by a simple chemical solution route. Langmuir, 2004, 20(8), 3441-3448.
17. Chai Z., Liu Y.H., Lu X.C., He D.N., Reducing adhesion force by means of atomic layer deposition of $\mathrm{ZnO}$ films with nanoscale surface roughness. ACS Appl. Mater. Inter., 2014, 6(5), 3325.

18. Chai Z.M., Liu Y.H., Lu X.C., He D.N., Reducing friction force of si material by means of atomic layer-deposited zno films. Tribol. Lett., 2014, 56(1), 67-75.

19. Rajasekar R., Kim N.H., Jung D., Kuila T., Lim J.K., Park M.J., et al., Electrostatically assembled layer-by-layer composites containing graphene oxide for enhanced hydrogen gas barrier application. Compos. Sci. Technol., 2013, 89(5), 167-174.

20. Auclair-Daigle C., Legoux B.G., Bioactive hydroxyapatite coatings on polymer composites for orthopedic implants. J. Biomed. Mater. Res. A, 2010, 73A(4), 398-408.

21. Oh I.H., Nomura N., Chiba A., Murayama Y., Masahashi N., Lee B.T., et al., Microstructures and bond strengths of plasmasprayed hydroxyapatite coatings on porous titanium substrates. J. Mater. Sci. Mater. Med., 2005, 16(7), 635-640.

22. Chen Y.F., Zhang T., Tang M., Xie D., Long Q., Li C.Y., The effect of high-current pulsed electron beam modification on the surface wetting property of polyamide 6. e-Polymers, 2017, 17(1), 23-29.

23. Duan B., Wang M., Li Z.Y., Chan W.C., Lu W.W., Surface modification of three-dimensional Ca-P/PHBV nanocomposite scaffolds by physical entrapment of gelatin and its in vitro biological evaluation. Front. Mater. Sci., 2011, 5(1), 57-68.

24. Ai C.C., Cai J.Y., Zhu J., Zhou J., Jiang J., Chen S.Y., Effect of PET graft coated with silk fibroin via EDC/NHS crosslink on graft-bone healing in ACL reconstruction. RSC Adv., 2017, 7(81), 51303-51312. 